\title{
A Chinese palaeontologist, Ma Ting Ying (1899-1979): From coral growth-rings to global tectonics
}

\section{Introduction}

Ma Ting Ying was a Chinese palaeontologist who became well known for his researches on coral growth in relation to sea-water temperatures. His contributions to geology were, however, wideranging: from palaeontology to economic geology (such as matters to do with petroleum and salt), and from geological science to geological education. His interests also covered glaciology and loess studies (Ma, 1938a, 1940, 1941). As chief of the Oceanographic Section of the Geographical Institute, China, he led a survey of the coast of Fujian, the only marine survey conducted by China during the War period. In his later career, Ma became involved in the 'high theory' of tectonics. The present paper focuses on his contributions in palaeontology (with emphasis on his studies of coral growth rates, which were related to the 'palaeontological clock'), palaeoclimatology, and his thoughts about tectonics. His work on coral growth rate and mobilist theory was influential, in part because a good deal of it was written in English. We shall, therefore, say something about Western opinions of his work.

\section{Brief profile of Ma Ting Ying}

Ma Ting-Ying was born in 1899 into a farming family in County Jin, Liaoning Province, China. Inspired by the 'saving our country by science' movement, he decided to go to Japan for study in 1917, when he was only eighteen. There he enrolled at the Normal College, Tokyo, where he studied natural history. After finishing his studies with an excellent academic record, Ma was accepted as a research student in the Department of Geology of Tohoku Imperial University, Japan, and in 1929 he started as a PhD student under the famous Japanese geologist and palaeontologist, Hisakutsu Yabe (1878-1969).

As a Chinaman, Ma's period as a research student was a difficult time for him, when there was tension between China and Japan, even before the Japanese invasion; and he would have been unable to continue his doctoral research without financial support from Ting Wen Jiang, General Secretary of the Academia Sinica. Ma also received support from the National Research Institute of Biology of the Academia Sinica, enabling him to carry out studies on Pratas Island (a small island in the South China Sea between Hong Kong and the northern Philippines), from April to September, 1935.

Ma did not simply encounter financial problems. In 1936, having finished his $\mathrm{PhD}$, he started his return journey to China, but was pursued and nearly captured by the Japanese military police, with the pretext that he was taking away important scientific secrets. Fortunately, however, owing to Professor Yabe's intervention, Ma was allowed to return home (Pan Yuntang, 1996, p. 388).

After his return from Japan, Ma took up positions as a researcher at the Geological Survey of China, and Professor at the National University. After 1939, he worked at the Oceanography Section, of the Geographical Institution of China. In 1945, Ma was dispatched to the University in Taipei, formerly called the Imperial University of Japan, where he organized the Department of Geology. Subsequently, he was appointed professor there, a position he occu- pied until his retirement. From 1946 to 1950, Ma also acted as Director of the Oceanographical Institute of Taiwan. He died of stomach cancer on 15 September, 1979 (Sun, 1987, pp. 45-47).

\section{Ma's contribution to geosciences}

\section{Coral growth}

Studies in palaeontology developed rapidly in China after 1920. Most of the work was concerned with classification, anatomical description, or biostratigraphy, but Ma focused on studies in biological rhythms, and initiated studies in palaeoecology, palaeoclimatology, and palaeogeography. He studied the growth-rate changes of corals, which eventually led to the discovery of the 'palaeontological clock' and had a worldwide influence.

As early as the nineteenth century, there were already studies on the growth-rates of living corals. For example, Robert Parr Whitefield (1898) described the annual growth increment of a large colony of the reef coral Acropora palmate. In the second decade of the twentieth century, Thomas Wayland Vaughan (1915) obtained growth estimates of 40-100 mm/year-much the same as the results from measurements of the growth 'undulations' found in Whitefield's specimens. Vaughan studied the growth rate of Orbicella annularia Dana, and estimated that it would require approximately 6,500 to 7,600 years for corals to build a reef 150 feet thick (= 49.2 metres). Another study came from John Stanley Gardiner (1903, pp. $327-333$ ), who calculated that it would require about 1,000 years for a coral reef to attain a thickness of 14.5 fathoms (=26.5 metres). A similar figure of 1,000 years for coral reefs to become 13.5 fathoms (= 24.7 metres) thick was calculated by A. G. Mayor (1924, pp. 51-72). The most accurate figure, in Ma's opinion, was that obtained by Torahiko Terada (1878-1935) (1934). Based on Ma's data, Terada calculated coral growth-rates for reefs on some of the circumPacific islands. He found that the density of reef-building coral was 1.5 , whereas that of the reef limestone was 2.7 , the ratio between the two thus being 1:1.8. Hence Terada deduced that if 540 metres of coral yielded 300 metres of limestone, and if the growth-rate of reef coral was 5.4 millimetres per year, then it would take $10^{5}$ years to form 300 metres of limestone reef. Similarly, he calculated that the times required for the formation of the 1,000-feet ( $=305$ metres) thick Funafuti reef and the 200-metre thick reef of Daito-zima (an island off Japan) were $10^{6}$ and $10^{5}$ years respectively (Ma, 1936, p. 298).

Under Professor Yabe's supervision, Ma had been studying the Palaeozoic corals held in the Institute of Geology and Palaeontology, Tohoku Imperial University. Initially, he selected six specimens for study: "two haploid Silurian corals from Visby, Gotland, two cerioid Middle Devonian forms from Eifel, Germany, a phaceloid Upper Devonian form from Iberg, Germany, and a haploid species from the Lower Carboniferous of the Avon section, England" (Ma, 1933, p. 407). In this early paper, Ma found that the specimens exhibited periodic changes in the growth of their interseptal tissue, the dissepiments and tabulae having different densities at different heights above the base of the corallites. There were usually two consecutive, but different, layers. One had minute, densely crowded dissepiments and tabulae, while the other possessed larger, less crowded dissepi- 
ments and tabulae; and together they formed a set. He suggested, then, that the different layers might represent annual cycles of growth in response to seasonal temperature changes, as could be found for some living reef corals (Ma, 1933, p. 407). Thus, Ma announced his discovery of seasonal changes in the growth of some Palaeozoic Tetracorals. But this did not in itself provide evidence for a general relationship between water temperature and coral growth, or that there had been different climatic zones in past geological periods.

Next, Ma (1934a, 1934b) extended his studies to recent reefbuilding corals, in order to ascertain whether or not the same phenomenon might be found today. Of special importance was the fact that the annual increase in a coral's length, measured at a certain locality in the Pacific, could be correlated with the periodic increase of growth exhibited in the inner structure of the same species from the same locality (Ma, 1934a).

From April to September, 1935, Ma, with Ting's recommendation, obtained a grant from the National Research Institute of Biology of the Academia Sinica to pursue his studies of corals and coral-reefs in the South China Sea. His aim was to use information about the growth-rate of living corals for arguments about climates in geologically recent time. He examined coins that had been dropped near Paracel Island in the South China Sea $\left(17^{\circ} 0^{\prime} \mathrm{N} ; 111^{\circ} 35^{\prime} \mathrm{E}\right)$ by wrecked schooners, which were now covered by about five feet of coral. The coins were dated between 1408 and $1424 \mathrm{AD}$, so about five feet of coral had formed in about five hundred years. This gave an annual growth-rate of about $3 \mathrm{~mm} /$ year (Ma, 1936) - a figure that was much the same as Terada's.

A further study (Ma, 1937a) not only showed that the annual growth-feature was found in the internal structures of recent reefbuilding corals, but also there was a correlation between these structures and the external annulations or growth swellings of corals. This coincidence was also found in Atlantic corals. Ma (1937d, p. 17) pointed out that the external annulations, which corresponded to the internal structure of the corals, were indicative of seasonal or annual growth and might be analogous to the annual growth-rings of trees. The same year, Ma again emphasized that "annulation indicate[d] the annual cycle of growth in response to the seasonal change of the water temperature under which the animals had lived" (Ma, 1937c, pp. 8-9).

As the number of specimens examined increased tremendously, Ma began to analyse the results statistically and generalizations began to emerge. In his paper on the relation between reef corals' growth-rate and sea-water temperature (1937d) Ma tabulated data on 'Genus and Species', 'Region', and 'Growth Rate', with 2,856 specimens being examined. He further found that for Palaeozoic Tetracorals, Mesozoic Hexagonaria, and modern Hexagonaria there was both annual and seasonal growth, in both the internal and external structures. Then, using a 'Growth-Temperature' graph, based on modern data, he was able to estimate former sea temperatures from observation of the annual growths of fossils (Ma, 1938b, p. 350).

\section{Corals and change in rate of the Earth's rotation}

In the 1960s, the American Cornell University geologist and palaeontologist John W. Wells published what came to be a wellknown paper entitled 'Coral Growth and Geochronometry' (Wells, 1963). After reviewing the development of geochronometry and previous studies of annual fluctuations in coral growth, he announced an amazing discovery, namely that diurnal growth-rings of corals could be used to corroborate the astronomical hypothesis of the gradual retardation of the Earth's rotation (ascribed to tidal friction). Wells's research showed that for Devonian corals, such as Heliophyllum, Eridophyllum, and Favosites from New York and Ontario, there were 385-410 diurnal growth-lines per annum. But there were 390 lines per annum for Carboniferous corals Lophphyllidium and
Caninia. This agreed with a graph (given in the paper) comparing radiometrically determined ages and the number of days in a year, according to the calculations of astronomers based on considerations of tidal friction. From the evidence of the corals, the number of days in a year would be 385-410 in the Middle Devonian, 390 days in the Pennsylvanian, as compared with approximately 360 days in modern times. The conclusion was that the Earth's rate of rotation had slowly but steadily decreased from ancient times. This palaeontological research supported the idea of a decrease in the Earth's rate of rotation, based on astronomical (Munk \& MacDonald, 1960) and radiometric/stratigraphic (Kulp, 1961) datings and arguments. Wells was gratified that palaeontology could lend support to the abstract calculations of the physical sciences. There was now the possibility of using the measurement of coral growth-rings as a geochronometer. (However, in the event the method has not proved sufficiently precise to be of much general practical importance.)

In 1965, Colin Scrutton, of the University Museum, Oxford, published 'Periodicity in Devonian Coral Growth', in which he grouped about thirty fine coral growth-ridges - indicative of diurnal increments as Wells had proposed-into regular bands. After considering other possible causes, Scrutton (1965) argued that the banding was very likely related to a lunar breeding periodicity, and that the Middle Devonian year contained 13 lunar months, each having $301 / 2$ days. It was, then, Wells and Scrutton's discoveries that really took up the challenge from astronomers, who had hoped that palaeontological evidence might corroborate their ideas about changes in the length of the day. But previous workers, and notably $\mathrm{Ma}$, provided the foundations for the subsequent great discovery of the gradual slowing-down of the Earth's rotation.

However, while Wells noted Ma's investigations of the variation of annual growth increments in recent and fossil corals, and he stated that "Ma's basic idea that annual growth-rates c[ould] be determined for many fossil corals appear[ed] to be sound" (Wells, 1963, p. 950), he also said that Ma "assembled an appalling mass of very raw data on which he ... leaped from assumption to assumption to heights of speculation where few would care to follow"!

Only one of Ma's papers was referenced by Wells. In that paper, Ma had sought to illustrate the relationship between the "periodic change of growth in the recent as well as fossil corals" and the "seasonal change of the water temperature under which the polyps lived" (Ma, 1934a, p. 354). But Ma did not there touch on anything concerning past changes in the position of the equator or continental drift. While Wells had no objection to Ma's empirical work on corals, he was not impressed by his other papers, with their extensive mobilist speculations.

Wells's preference was for empirical research, and, as said, he was led thereby to the discovery of a 'palaeontological clock'. By contrast, Ma was a pioneer in palaeoclimatology and palaeogeography and his coral work eventually led him to explore grand problems in tectonics. Thus in the early 1960s, on the eve of the birth of new tectonic theory, Ma became an active advocate of continental drift theory, whereas Wells was distancing himself from speculations where "few would care to follow".

While speculating freely on tectonic theory (as will be discussed below), Ma was conservative in discussing the idea of variation in the Earth's rate of rotation. His reasoning was as follows. It appeared that the annual growths of Silurian corals were almost the same as those of modern times. But (he thought) if the Earth rotated more rapidly in the Silurian than at present, the length of a year in the past would have been less than now ${ }^{1}$ so that the coral growth-period in the past would have been shorter than in the modern times, whence it would appear that the climate in the Silurian was warmer than at present. But this seemed incorrect to $\mathrm{Ma}$, since the breadths of the equatorial coral belts in the Ordovician and Silurian appeared to have been similar to those we have today. Therefore, Ma held: "We can agree that the Earth's rotation rate in past geological times

${ }^{1}$ We do not accept Ma's opinion on this point, since the length of a year is decided by the revolution of the earth round the sun, not its axial rotation. 
has changed, but the change must be very limited, and its rotating rate at the beginning of the Palaeozoic Epoch was roughly the same as now" (Ma, 1943b, v. 2, p. 8 [Chinese section of text]). In fact, he thought that the Earth's climate (or temperature) "had been fixed long ago" (Ma, 1943c, v. 3, p. 7). So Ma and Wells made significantly different inferences from the coral data.

\section{Palaeoclimatology}

As we have seen, Ma deduced that corals, either living or fossil, like trees, manifested seasonal growth. Ma (1934b) also suggested that the same species of coral exhibited greater annual growth in warmer regions and less in cooler regions, and that the same individual exhibited more annual growth in warm years and less in cool years. That is, water temperatures and annual growth of corals were intimately related. Ma (1937d) gave the results of the measurements of the growth rate of 177 species and 11 sub-species in 56 genera collected from the Pacific, Indian, and Atlantic Oceans. The relation between the coral growth-rate and sea-water temperature in the coldest months was expressed in a 'Growth-Temperature Graph', on the basis of which Ma argued that:

there exists a direct positive correspondence between the increasing length or expansion of annual growth of corals and the increasing temperature of water. Accordingly, corals of the same genus and species living at different localities in water of similar temperature are found to show closely similar length or expansion of annual growth (Ma, 1937d, pp. 20-21).

Therefore, studies on the length or expansion of the annual growth in reef-building corals of past ages were considered relevant to the study of past climatic conditions

Thus, using corals, Ma (1934b) made extensive and intensive researches concerning sea-water temperatures during various geological times at different places. He pointed out that the sea-water temperature in the area of the Japanese archipelago had been much warmer during the early Holocene than in Recent times, and also during the formation of the Early Pleistocene Ryukyu Limestone. Ma published several other papers expounding his ideas about the relation between coral growth rates, sea-water temperatures, and palaeoclimates. For example, Ma (1937a, p. 177) claimed that the annual increase in length is greater in corals from what are now Arctic regions and some states of the United States than in those from what is now northern Europe; and seasonal change of growth was developed remarkably in the corals from the latter region, while it was hardly observable in specimens from the former region. These facts suggested different climatic environments.

Then Ma (1937a, pp. 177-178) made a striking claim, namely that significant climatic differences existed during the Ordovician in different regions of the northern hemisphere that presently have similar high latitudes. Two years later, Ma pointed out that there were obvious climatic differences between the lower and upper Palaeozoic, according to the corals' seasonal growth phenomena, and "this fact ... [was] against the contemporary opinion that climatic differences began after the Carboniferous Period" (Ma, 1939, pp. 395-396). In his paper 'On the Seasonal Growth in Palaeozoic Tetracorals and the Climate during the Devonian Period' Ma (1937c, pp. 43-44) demonstrated that during the Devonian, the temperature of the seas in the area of what is now Germany appeared to have been cooler than those of France and England, Hunan and Kwangxi in Southern China, and Chitral and Northern Shan State, India. Moreover, the temperature of the Devonian seas of England was seemingly higher than that of France. And the temperatures of the Devonian seas of New York and Maryland in North America were seemingly warmer than that of Missouri, as well as Germany, whereas Anatolia and Asia Minor were apparently cooler than Germany. From such information, Ma inferred that the Devonian equator passed through Timan and the Urals in northern Russia, and through Sichuan and Yunnan in China, even though data about seasonal changes of growth-rate in those places were wanting (as Ma acknowledged). It was from such findings that Ma began to consider the implications of his coral work for the theory of continental drift. For in order to explain why the equator was aligned differently in the past as compared with the present, and why it seemingly did not form a closed or complete circle, he had to invoke pole wandering and movements of the continents relative to one another.

\section{An advocate of continental drift}

Alfred Wegener put forward his continental drift theory in 1912 (Fritscher, 2002). For reasons that are well known, his idea was not accepted by the majority of geoscientists, especially geophysicists and particularly in America (Oreskes, 1999). After Wegener died in 1930 , interest in and controversies about his hypothesis gradually declined. Nevertheless, some scientists went on pondering the theory, and Ma was one of them. From 1943 onwards, he published a series of short works, privately published, which strongly advocated drift theory: Past Climate and Continental Drift (1943-1966, 19 volumes).

As we have seen, when Ma was a PhD student in Japan, he studied the growth-rates of Palaeozoic corals, and supposed that different growth-rates suggested different climates and former different geographical positions for the various regions of the globe. Hence he deduced that the position of the equator in the Devonian was not the same as it is at present. The fact that corals of the same genus and species living in different regions of similar temperature exhibited similar annual expansion of growth "induced him to undertake the research in this direction in the spheres of palaeoclimatology and the problem of relative movement of continents" (Ma, 1943a, v. 1, p. 1). Later, Ma began a systematic study of seasonal changes of coral growth-rates at various geological epochs and deduced the relative positions of various continents. For instance, in the Ordovician, the annual increase in length of corals in the British Isles and Norway was somewhat greater (for the same species or genus) than that from Estonia, Lithuania, and Germany; but the annual increase of the same species or genus of corals from Anticosti Island (in the Gulf of St Lawrence) or New York State was not distinctly different from that in those of British Isles and Norway. Hence, he deduced that "the positions of British Isles and Norway in the Ordovician Period had to be near or in contact with those of New York State and Anticosti Island, or the distances from these places to the equator at that time were equal or nearly so" (1943a, v. 1, p. 26). Thus, Ma thought that, during the Ordovician, Eurasia and North America were much closer to one another than they are at present, or were even attached, instead of being separated by thousands of miles of Atlantic Ocean. Hence, the idea of continental drift was strongly supported.

Moreover, Ma (1943a, v. 1, p. 26) suggested that it was possible for the poles to have shifted during past geological times. The positions of Ordovician poles could be deduced from the apparent position of the equator at that time, as inferred from the growth-rates and the degree of seasonal differences in coral growth. Overall, the coral seas for various geological periods ran obliquely away from the present tropics, at different angles for the different continents, as these are presently situated, and not on the same great circle as that on which the equatorial belt lies at present.

In 1947, Ma suggested that the position of Eastern Asia increased by some $10^{\circ}-14^{\circ}$ from Middle Pliocene $\left(22^{\circ}-27^{\circ} \mathrm{N}\right)$ to Upper Pliocene, due to movement of the geographical poles (Ma, 1947b, p. 6). (The use of pole wandering as an explanatory device in geology was an old one, going back at least to Robert Hooke in $17^{\text {th }}$ century England; but we doubt that Ma picked up the idea from that source.) He argued on the basis of submarine canyons and plains found near Taiwan, and fossil plants discovered by Yabe in Kyushu, Japan, which seemed to be types that indicated a former colder climate than that found there today, according to analogies with modern species. It was suggested, then, that in the Pliocene the land where Kyushu is now situated could have been at an altitude 1,000 metres (or more) higher than at present. One might think that this could have been due to global climate change, or to a southward 
movement of Asia from a colder region. But Ma offered a third alternative, namely that equatorial land had moved northwards (due to polar wandering), to a region where the Earth's radius would 'naturally' be less than that at the present equator (because of the oblately spheroidal shape of the planet). So pole movement that produced a northward movement of the equatorial region would have left some of the land to the north 'high and dry'; and there could have been a land bridge between Asia and the Americas in the higher latitudes. A subsequent 'collapse' of the elevated land could have occurred, accompanied by volcanic activity, yielding the modern configurations. The submarine canyons and plains by Taiwan could be erosion surfaces on land that was formerly above sea level. Ma (1947b, p. 5) claimed that the changes of altitude suggested by the fossil evidence and the depth of the submarine erosion features were mutually consistent. Additional movement was also suggested during the Pleistocene (Ma, 1947a). Thus the issue of the elevation of north Asia was supposedly dealt with chiefly by pole wandering. Ma (1949)

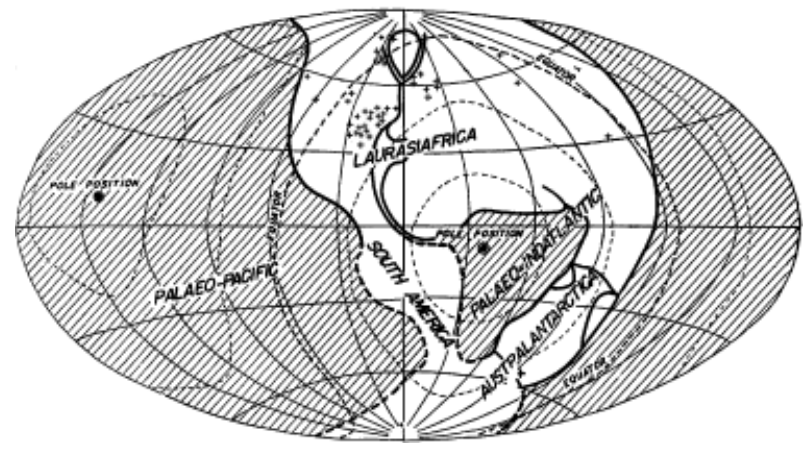

Figure 1 The equator and the relative positions of continents during the Ordovician period.

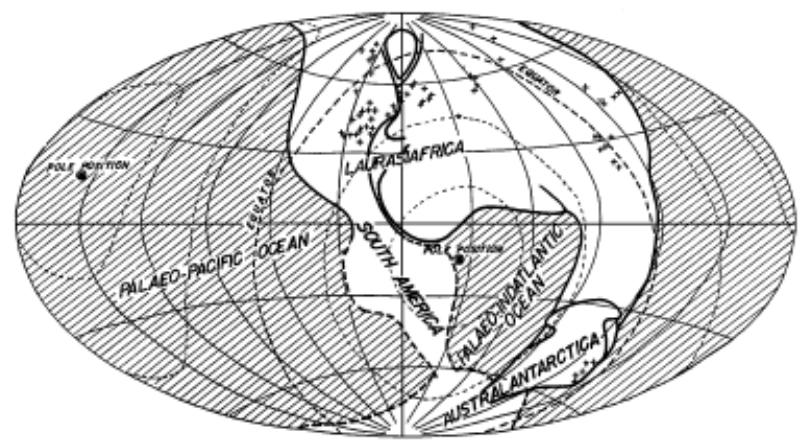

Figure 2 The equator and the relative positions of continents during the Silurian period.

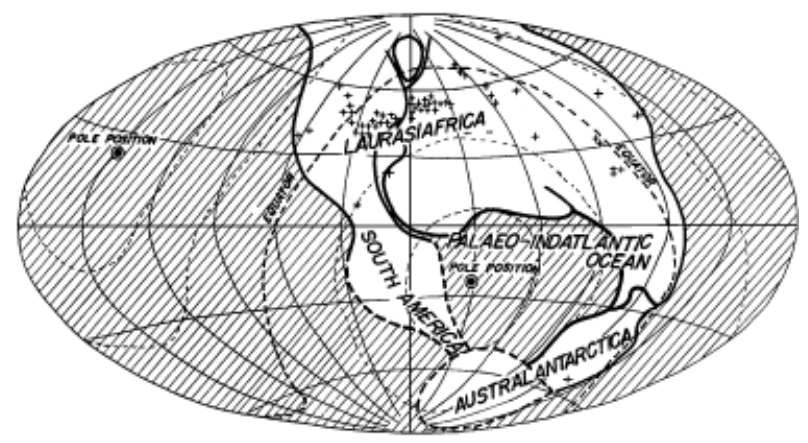

Figure 3 The equator and the relative positions of continents during the Devonian period. sought to confirm the occurrence of three upheavals in the Pliocene/Pleistocene by palaeontological and pedological evidence with suggestions as to how warm and cold oceanic currents might have shifted as a result of the pole-shifts and consequent tectonic movements.

Subsequently, Ma's ideas about the former positions of the equator and the positions of continents were summarized in pictorial form, as shown in Figures 1 - 6 (Ma, 1957, pp. 4-9).

\section{Tectonic speculations}

Ma sought to account for the kind of evidence described above, and also the origins of oceanic volcanoes and island arcs, in his papers 'The Sudden Total Displacement of the Outer Solid Earth Shell by Sliding Relative to the Fixed Rotating Core of the Earth' (Ma, 1953), 'An Orogenic Interpretation of Island Arcs' (Ma \& Pan, 1955), and 'Continental Drift and the Present Rate of Movement of the Conti-

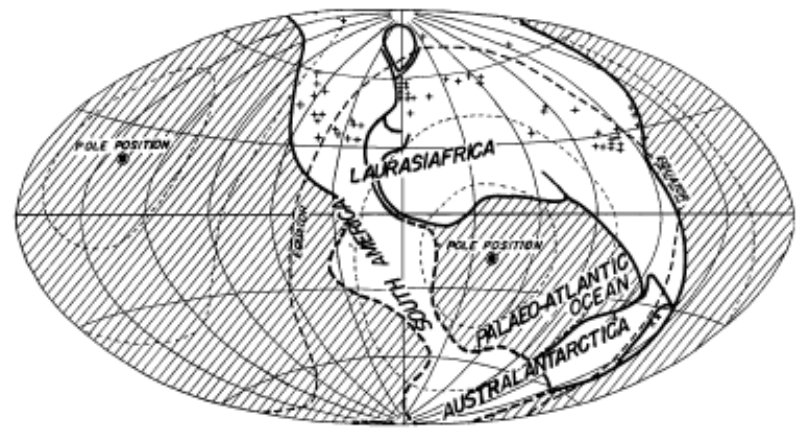

Figure 4 The equator and the relative positions of continents during the Lower Carboniferous period.

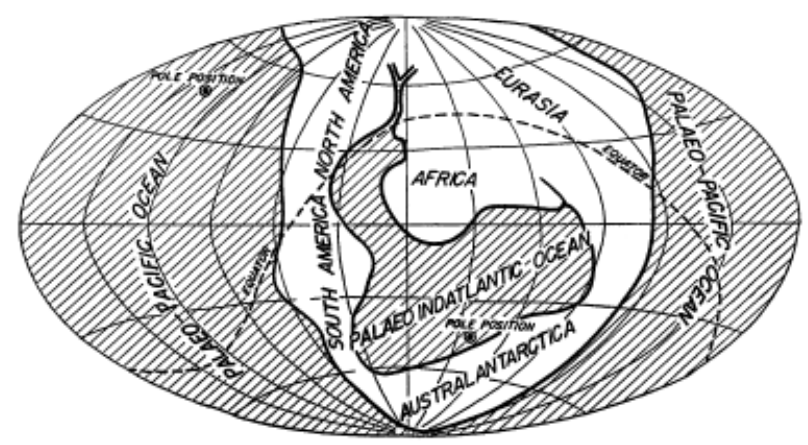

Figure 5 The equator and the relative positions of continents during the Cretaceous period.

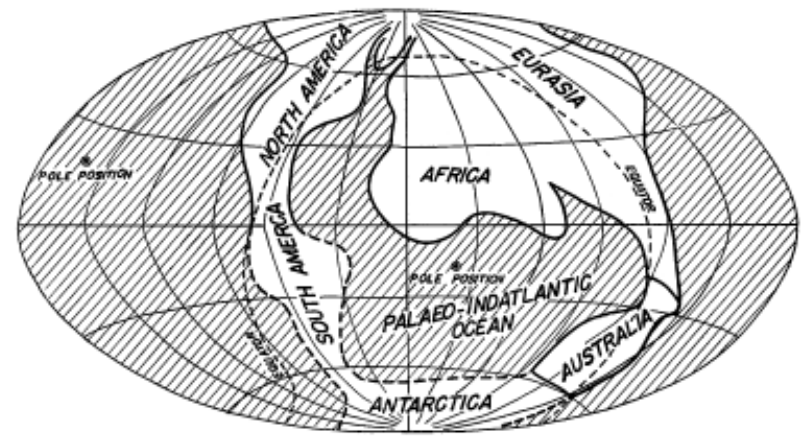

Figure 6 The equator and the relative positions of continents during the Oligocene period. 
nental Margin of Eastern Asia' (Ma, 1957). In his earlier work, he suggested Wegenerian 'drifting': movements of the rocks of the present continents relative to one another, bringing former equators of different continents 'into line', so as to be able to delineate continuous equatorial belts on his maps. Thus the evidence from the minute details of corals, given sufficient statistical backing, was held to support 'drift' theory.

But from 1949, following the adumbration of his ideas in 1947 that were discussed above, Ma went beyond Wegener's ideas and tried to develop a theory to account for his evidence in terms of the internal movements of the globe (Ma, 1953). As he explained, and as we might expect, the origin of his speculations came from his coral studies. The apparently constant width of the equatorial belt through geological time suggested an overall uniformity of climate, despite movement of the poles. So climatic changes in different regions were ascribed, not to global warming or cooling, but to shifts in latitude (demonstrated by the evidence from corals) and temporary land elevation, consequent upon changes in the positions of the poles (Ma, 1953, p. 3)

In concluding his paper, Ma acknowledged the assistance of "Mr. Pan Chia-lin, who ha[d] followed his researches for many years, . . . deducing the cause of the sudden sliding of the solid earth shell over the liquid core according to physical principles" (Ma, 1953 , p. 13). Thus the theory suggested may well have come primarily from Pan; but regrettably we have no information about this man. Be this as it may, Ma wrote:

\section{A rotational body such as the earth should not change its axis of rotation without an additional force or torque to shift it by the superposition of another component or angular velocity. The drift of continents causes an uneven distribution of mass away from the equator to continuously exert such a torque which would at first cause a precession of the axis of rotation. When the precession attains sufficient magnitude to cause a sudden breaking up of the solid earth shell the pieces could be thrown in a certain direction so that the precession would be suddenly transferred entirely to the solid parts leaving the liquid core to resume its original axis of rotation without precession (Ma, 1953, p. 5).}

He assumed from seismic evidence that the solid/liquid boundary within the Earth was at a depth of about 7/15ths of its radius. So, he continued:

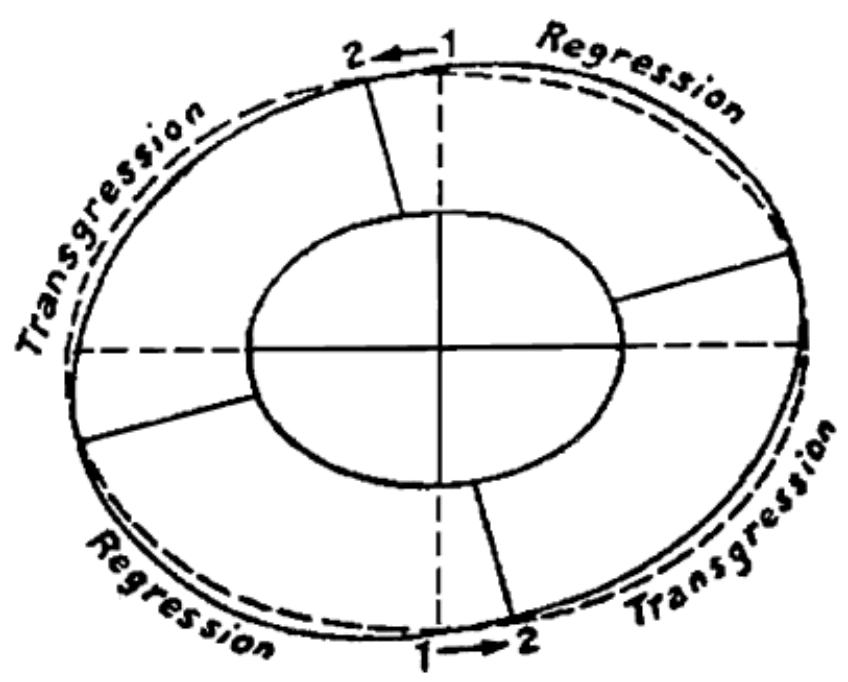

Figure 7 The distorted shape of the earth after a sudden sliding of the solid shell. 1 the fixed axis of rotation. 2 the point situated at the pole before the sliding. The dotted ellipse is the normal sea level which represents the normal shape of the earth to which readjustment approaches.
The resulting precession of the parts of the solid earth shell as a result of the sliding of these parts with respect to the liquid core would be equivalent to a sudden change of latitudinal positions that would change the thickness of a place by about 7/15 the difference of earth radius at the new and old latitudes (Ma, 1953, p. 5).

The theory was illustrated by means of a sketch-diagram (see Figure 7 [Ma, 1952, p. 5]).

Ma then continued, by way of explaining his diagram:

The earth radius at the poles is 6,356.9119 kilometers and the radius at the equator 6,378.3880 kilometers and the radius at each latitude is different according to the elliptical shape. When the solid shell is suddenly displaced sea level still maintains the original elliptical shape. The solid earth surface would be uplifted with respect to sea level where a greater thickness of the earth shell shifts to a latitude where the normal thickness is smaller, and would subside visa [sic] versa. The abnormal thickness at respective latitudes would resume normality with the sudden uplifts followed by slow subsidences or visa [sic] versa, leaving the corresponding geological and climatic evidences which can only be explained by such a process of epeirogenesis (Ma, 1953, pp. $5-6)$.

He again pointed out that the occurrence of submarine canyons suggested the drowning of former land surfaces; and the evidences of glaciation at places that now have low latitudes, or warm climate deposits found at high latitudes, would indicate movement of poles.

The theory hardly seems satisfactory, however, since it appears to be circular. Continental movements were to be explained. But they were invoked to account for the torque that would lead to the changed precession effects, deemed to be responsible for the tectonic activity described above.

Be that as it may, Ma's ideas were further developed in 1957, following the publication of Hugo Benioff's (1954) work on the seismic evidence for deep fault-zones. Ma again invoked the notion of the "sudden total displacement of the solid earth shell" (Ma, 1957, p. 2 ) relative to the fluid interior. In his opinion, it was insufficient to consider only a few dozen kilometres of sial moving over sima, as in the older theories such as Wegener's. Tectonic activity was, Ma thought, likely to reach to $700 \mathrm{~km}$ below the surface. And for Ma, developing his previous ideas, Benioff shear zones were supposedly the product of the hypothesized sudden global movements of the 'solid earth shell':

Although the lateral shift of crustal masses during quiet geological times is too small to account for the large amounts of drift of the continents, the vertical uplift of the forward edges of crustal masses in different parts of the world causes torques due to the rotation of the earth that ... [do] not balance out. Such a torque causes a precession of the axis of rotation of the earth. The increase of the resultant torque as the forward edge of each crustal mass is uplifted more and more with time would cause the precession to increase to such magnitude that the solid earth shell would be thrown [so as] to slide over the liquid core. [Then t] he liquid core freed from the torque on the surface would resume rotation around the original fixed axis in astronomical space while the solid earth shell would suddenly suffer an angular displacement away from the original poles as far as the resultant torque can push it against the friction (Ma, 1957, pp. 19-20).

Here there was some advance over the proposal of 1953, for if the hypothesized crustal movements produced new 'imbalances' in the distribution of the masses of the Earth's crust, then, one may suppose, there could be new 'torques' developed, and the whole system would continually create new configurations, which would lead to new forces, which would lead to new tectonic adjustments, which 
would lead to new configurations, ... At least, that seems to have been Ma's belief. Presumably he supposed that primordial inequalities in the Earth's crust would lead to a perpetual succession of adjustments and tectonic changes.

\section{Responses to Ma's ideas}

Ma was, we have seen, a 'neo-catastrophist'. The basic idea of internal convection currents, used in modern plate tectonic theory, was absent from Ma's scheme-which was never much accepted, as regards his whole-Earth dynamic theory. His work was, however, introduced by David B. Ericson of the Lamont Geological Observatory to Charles H. Hapgood (who was then working on a study of pole wandering) in 1954. It was, according to Hapgood, Ericson who "took a leading role in introducing Ma's ideas to American scientists"(Hapgood, 2001, p. 80). Hapgood was an author whose ideas lay outside the mainstream of geological theorizing. He worked at a Liberal Arts College, Keene Teachers College, New Hampshire, where he developed the idea that unequal and asymmetrical polar ice-caps could disturb the Earth's rotation sufficiently to produce displacements of the crust, or pole wandering. Perhaps surprisingly, Hapgood managed to interest Albert Einstein in his views and Einstein wrote a foreword to Hapgood's book, Earth's Shifting Crust (1958) (republished as The Path of the Pole, 1970/2001), which apparently gave some credibility to the author's theory. Hapgood seems to have belonged to the 'Atlantis fraternity', but despite his marginal position his interest in Ma seemingly helped bring Ma's ideas to notice in the Western world (aided, of course, by the fact that he published much in English).

For a geological mainstream notice of $\mathrm{Ma}$, we may mention Derek Ager's Principles of Paleoecology (1963). As the term suggests, palaeoecology is the branch of science that seeks to study the 'conditions of existence' or environments of ancient organisms. But Ager did not think that the subject should be restricted to the study of local conditions of existence. Valuable information could be inferred from the study of world-wide distributions:

The world-wide distribution of a form may not appear at first sight to be an ecological subject, but it may have a direct relationship with such ecologically significant matters as climatic zonation and ocean currents.... All distributions are ecological matters ... (Ager, 1963, p. 148).

Later in his book (pp. 161-163), Ager went on to consider Ma's work, reproducing one of his figures (from Ma, 1954) which indicated a wide discrepancy between the Present and Lower Carboniferous equatorial lines. Moreover, it appeared that there was a break in the locus of the Carboniferous equator between the eastern and western hemispheres, which could be 'mended' by hypothesizing the occurrence of continental drift. Thus, as we have argued in the present exposition of Ma's work, much could be inferred from the study of global distributions. From the microscopic examination and statistical analysis of many thousands of coral dissepiments, great movements and changes of the Earth's crust-and concomitant climatic changesócould be inferred. These movements stood as 'facts' on the basis of Ma's work. His explanations thereof were wanting, but the coral data and the inferred continental movements provided one of the empirical bases on which modern plate tectonic theory could subsequently stand. We note also that the Australian Coral Records Research Group currently publishes summaries of Ma's work on the internet. He has not been forgotten.

\section{References}

Ager, Derek V., 1963, Principles of Paleoecology: An Introduction to the Study of How and Where Animals and Plants Lived in the Past. New York, San Francisco, Toronto \& London: McGraw-Hill Book Company. Ager, Derek V., 1981, Principles of Paleoecology: An Introduction to the Study of How and Where Animals and Plants Lived in the Past. Beijing:
Science Publishing House (in Chinese). Translation by Wang Yicheng from the English edition, 1963.

Benioff, Hugo, 1954, Orogenesis and Deep Crustal Structure-Additional Evidence from Seismology. Bulletin of the Geological Society of America, v. $66,385-400$.

Fritscher, Bernhard, 2002, Alfred Wegener's "The Origin of Continents", 1912. Episodes, v. 25, 100-106.

Hapgood, Charles H., 1958, Earth's Shifting Crust: A Key to some Basic Problems of Earth Science. Pantheon Books.

Hapgood, Charles H., 1970, The Path of the Pole. Clifton Book Co., Philadelphia.

Hapgood, Charles H., 2001, The Path of the Pole (First British Edition). Souvenir Press Ltd, London.

Kulp, J. Laurence, 1961, Geological Time Scale. Science, v. 133, 1105-1114.

Ma, Ting-Ying H., 1933. On the seasonal change of growth in some Palaeozoic corals. Proceedings of the Imperial Academy [of Japan], v. 9, 407409.

Ma, Ting-Ying H., 1934a, On the Seasonal Change of Growth in a Reef Coral, Favia speciosa (Dana), and the Water-temperature of the Japanese Seas during the Latest Geological Times. Proceedings of the Imperial Academy [of Japan], v. 10, 353-356.

Ma, Ting-Ying H., 1934b, On the Growth Rate of Reef Corals and the Sea Water Temperature in the Japanese Islands during the Latest Geological Times. Science Report of the Tohoku Imperial University, Sendai, Japan, Second Series (Geology), v. 16, 165-189.

Ma, Ting-Ying H., 1936, Reef Corals and the Growth rate of Corals along the Sea of China. Geological Review, v. 1, 295-300 (in Chinese).

Ma, Ting-Ying H., 1937a, On the Growth Rate of Calapoecia canadensis Billings and the Climate of the Arctic Regions during the Ordovician Period, Bulletin of the Geological Society of China, v. 17, 177-182.

Ma, Ting-Ying H., 1937b, Data on the Time Required for the Building of Coral Reefs. Bulletin of the Geological Society of China. v. 17, 135-136.

Ma, Ting-Ying H., 1937c, On the Seasonal Growth of Palaeozoic Tetracorals and the Climate during the Devonian Period. Palaeontolgica Sinica, Series B, v. 2, fasc. 3, 1-106.

Ma, Ting-Ying H., 1937d, On the Growth Rate of Reef Corals and its Relation to Sea Water Temperature. Palaeontologica Sinica, Series B, v. 16, fasc. 1, 1-226.

Ma, Ting-Ying H, 1938a, On Asian Climatic Change in the Latest Geological Times, the Cause of Glacial Transgression and Regression and Topography in Sea Floor, Geological Review, v. 3, 119-130 (in Chinese).

Ma, Ting-Ying H., 1938b, On the Water Temperature of the Western Pacific during Early and Late Pleistocene as Deduced from the Growth Rate of Fossil Corals. Bulletin of Geological Society of China, v. 18, 349-418.

Ma, Ting-Ying H, 1939, On Climate in the Palaeozoic Era, Geological Review, v. 4, 395-412 (in Chinese).

Ma, Ting-Ying H, 1940, On Asian Geographical Environmental Change and the Formation of Loess Plain of China, Geological Review, v. 5, 1-20 (in Chinese).

Ma, Ting-Ying H, 1941, On Asian Climatic Change during the mid-Quaternary Period and the Cause of Glacier Formation, Geological Review , v. 6, 201-230 (in Chinese).

Ma, Ting-Ying H., 1943-1966, Research on Past Climate and Continental Drift, 19 vols. Yungan, Fujian and Taipei: Published by the Author. (All volumes have English and Chinese versions.)

Ma, Ting-Ying, H. 1943a, Research on Past Climate and Continental Drift (v 1): The Climate and the Relative Positions of Eurasia and North America during the Ordovician Period, as Determined by the Growth Rate of Corals.

Ma, Ting-Ying, H., 1943b, Research on Past Climate and Continental Drift (v. 2): The Climate and the Relative Positions of Continents during the Silurian Period, as Determined by the Growth Rate of Corals.

Ma, Ting-Ying, H., 1943c, Research on Past Climate and Continental Drift (v. 3): The Climate and the Relative Positions of Continents during the Devonian Period, as Determined by the Growth Rate of Corals.

Ma, Ting-Ying, H., 1947a, The Cause of Uplift of Eastern Asiatic Continent during the Middle Pleistocene Time. Bulletin of the Oceanographical Institute of Taiwan, No. 2, pp. 13-19.

Ma, Ting-Ying H., 1947b, The Upheaval Movement in Eastern Asia at the End of the Tertiary and the Cause Thereof. Bulletin of the Oceanographical Institute of Taiwan, No. 3. pp. 1-8.

Ma, Ting-Ying H., 1949. The Influence of Crustal Movements on Oceanic Climate in Asia since the End of the Tertiary. Bulletin of the Oceanographical Institute of Taiwan, No. 5, pp. 1-10.

Ma, Ting-Ying H., 1953, Research on Past Climate and Continental Drift (v. 6): The Sudden Total Displacement of the Outer Solid Earth Shell by Slidings Relative to the Fixed Rotating Core of the Earth. 
Ma, Ting-Ying H., 1954, Climate and Relative Positions of the Continents during the Lower Carboniferous Period. Acta Geologica Taiwanica, v. 7 , $1-86$.

Ma, Ting-Ying H. \& Pan, Chia-Lin, 1955, Research on Past Climate and Continental Drift (v. 8): An Orogenic Interpretation of Island Arcs.

Ma, Ting-Ying H., 1957. Research on Past Climate and Continental Drift (v. 12): Continental Drift and the Present Velocity of Shift of the Continental Margins of Eastern Asia.

Mayor, A. G., 1924, Growth-rate of Samoan Corals, paper from The Department of Marine Biology of the Carnegie Institution of Washington, v. 19, 51-72.

Munk, Walter H. \& MacDonald, Gordon L. F., 1960, The Rotation of the Earth: A Geophysical Discussion. Cambridge: Cambridge University Press.

Oreskes, Naomi, 1999, The Rejection of Continental Drift: Theory and Method in American Earth Science. New York \& Oxford: Oxford University Press.

Pan Yuntang, 1996, Ma Ting Ying, in: Biography of Scientists and Technological Experts of China, Volume 1, Earth Sciences, edited by Liu Dongsheng, 388-399. Shijiazhuang: Hebei Education Press (in Chinese).

Scrutton, Colin T., 1965, Periodicity in Devonian Coral Growth. Paleontology, v. 7, 552-558.

Sun Guanlong, 1987, Ma Ting Ying, Geological Professor at Taiwan University, China Historical Materials of Science and Technology, v. 8, 4547 (in Chinese).

Terada, Torahiko, 1934, Vertical Movement of Earth's Crust and Growth of Coral Reef, Proceedings of Imperial Academy [of Japan], v. 10, 643-645.
Vaughan, Thomas Wayland, 1915, The Geologic Significance of the Growthrate of the Floridian and Bahaman Shoal-water Corals, Journal of the Washington Academy of Science, v. 5, 591-600.

Wells, John W., 1963, Coral Growth and Geochronometry. Nature, v. 197, 948-950.

Whitfield, Robert P., 1898, Notice of a Remarkable Specimen of the West India Coral Madrepora palmata. Bulletin of the American Museum of Natural History, v. 10, 463-464.

\section{YANG Jing Yi}

Institute for the History of Natural Science

Chinese Academy of Sciences

137 Chao Nei Avenue

Beijing 100010

CHINA

\section{David Oldroyd}

School of History and Philosophy of Science

The University of New South Wales

Sydney, New South Wales 2052

AUSTRALIA

\title{
Hutchison 'Young Scientist' Fund
}

William Watt Hutchison, "Hutch" to his many friends around the world, was a Scots-born Canadian geologist who served Canada and the IUGS in myriad dynamic and creative ways. Most notably, he served as the IUGS Secretary General (1976-1980) at a pivotal time in its history, and as IUGS President (1984-1987). The same boundless energy, enthusiasm, skill in communications, and ability to foster teamwork that characterized his work with the IUGS also carried him to preeminent scientific administrative positions in the Canadian Government, where he served as Director General of the Geological Survey of Canada and as Assistant Deputy Minister of Earth Sciences. His distinguished career was terminated in 1987 by his untimely death at the age of 52, following a painful struggle with cancer.

One of Hutch's last wishes was to establish under IUGS auspices a memorial foundation intended to promote the professional growth of deserving, meritorious young scientists from around the world by supporting their participation in important IUGS-sponsored conferences. The first 3 beneficiaries of the Hutchinson "Young Scientist Foundation" attended the 28th International Geological Congress (IGC) in Washington, D.C., in 1989. However, income earned as interest on the Hutchison fund is insufficient to sustain comparable grants every four years without seriously eroding the principal. For that reason, the IUGS made no grants from the fund for the 29th and the 30th IGCs, preferring instead to strengthen the fund by allowing it to earn interest for a longer period of time and by appealing for donations from the international geologic community. And in 2000, 6 awardees received financial support from the Fund to attend the 31 st IGC in Rio de Janeiro, Brazil.

The Hutchison "Young Scientist Foundation" is a worthy cause that honors a fine, caring man and a distinguished, public-spirited scientist and administrator. The foundation also celebrates and promotes those things that gave Hutch the most professional satisfaction: geology, international scientific collaboration, and stimulating young minds.

The IUGS welcomes contributions to the Hutchison "Young Scientist Foundation." Please send donations to:

\author{
Dr. John A. Reinemund \\ 945 Oakwood Lane \\ Myrtle Beach, SC 29572 \\ Fax: 843-272-4128 \\ Tel: 843-361-9074
}

Checks in US dollars or Visa/Mastercard (please include account number and expiration date) are preferred in order to avoid the high cost of currency conversions. Residents of the U.S.A. are reminded that charitable gifts of this nature are tax deductible. 